\title{
A EDUCAÇÃO FÍSICA NO CONTEXTO DA EDUCAÇÃO DO CAMPO: a realidade do conteúdo jogo na escola
}

\author{
Nair Casagrande? \\ Fernanda Lima Ramos²
}

\section{RESUMO}

O presente trabalho é resultado do Projeto de Pesquisa "A Educação Física no Movimento dos Trabalhadores Rurais Sem Terra (MST): experiências pedagógicas a partir da Cultura Corporal". O estudo foi realizado em áreas de reforma Agraria do MST na região do Recôncavo da Bahia. O objetivo geral foi analisar a realidade da prática pedagógica do jogo, enquanto conteúdo de ensino da Educação Física, na Escola do Assentamento Nova Panema, no período de 2009/2011. A metodologia da pesquisa utilizou os instrumentos da observação participante, registros fotográficos e de campo, analise de documentos e entrevista semi-estruturada. Os resultados evidenciam que, apesar da Educação Física não constar como componente curricular no projeto político-pedagógico da escola, o conteúdo "jogo" estava presente na prática pedagógica da professora da turma multisseriada. Contudo, este vinha sendo utilizado na escola predominantemente como um instrumento de ensino ou como atividade recreativa.

Palavras-chave: Educação do Campo. Educação Física. MST. Jogo.

1 Pos-Doutoranda na School of Sport, Exercise and Health Sciences, da Loughborough University. Professora do Departamento de Educação Física da Faculdade de Educação da Universidade Federal da Bahia (UFBA). Salvador/Bahia, Brasil. E-mail: ncasagrande.ufba@gmail.com

2 Especialista em Metodologia do Ensino e da Pesquisa em Educação Física, Esporte e Lazer. Professora de Educação Física da Secretaria de Educação do Estado da Bahia. Salvador/Bahia, Brasil.

E-mail: fernandaramos08@yahoo.com.br 
julho/2017

PHYSICAL EDUCATION IN THE CONTEXT OF RURAL EDUCATION: THE REALITY OF THE CONTENT 'GAME' IN SCHOOL

\begin{abstract}
This paper presents the results of the research "Physical Education in the Landless Workers' Movement (MST): pedagogical experiences". The study was conducted in agrarian reform areas of the MST in the Recôncavo region, State of Bahia, Brazil. Its overall aim was was to analyze the reality of the pedagogical practice of the content game in Physical Education classes at the School of the Settlement New Panema, between the years 2009 until 2011. Data collection instruments used in this research consisted of the literature review, participant observation, analysis and semi-structured interviews. The results reveal that despite the physical education not having appear as a curricular component in the political-pedagogical project of the school, the content "game" was present in the pedagogical practice of multisseriate class. However, this was used only as a teaching tool for other fields of knowledge or as a recreational activity; not as a content of Physical Education classes.
\end{abstract}

Keywords: Rural Education. Physical Education. Landless Workers' Movement. Game.

\title{
EDUCACIÓN FÍSICA EN EL CONTEXTO DE LA EDUCACIÓN DO CAMPO: LA REALIDAD DEL CONTENIDO DEL JUEGO EN LA ESCUELA
}

\section{RESUMEN}

Este artículo presenta los resultados de la investigación "Educación Física en el Movimiento de los Sin Tierra (MST): experiencias de enseñanza". El estudio se realizó en áreas de reforma Agraria del MST en la región de Recôncavo de Bahía, Brasil. El objetivo fue analizar la realidad de la práctica pedagógica del juego, en la enseñanza de contenidos de la Educación Física en la Escuela Nueva Panema, en el periodo 2009/2011. La metodología de investigación utilizo la observación participante, registros fotográficos, análisis de documentos y la entrevista semiestructurada. Los resultados muestran que la educación física no es un componente curricular en el proyecto político-pedagógico de la escuela. Sin embargo, el contenido juego estuvo presente en la práctica pedagógica del maestro de la clase multiseriada y estaba siendo utilizado en la escuela como una herramienta de enseñanza de otros campos de conocimiento o como una actividad recreativa.

Palabras clave: Educación Rural. Educación Física. Movimiento de los Sin Tierra. Juego. 


\section{INTRODUÇÃO}

O artigo apresenta os resultados do Projeto de Pesquisa "A Educação Física no Movimento dos Trabalhadores Rurais Sem Terra (MST): experiências pedagógicas a partir da Cultura Corporal", realizado junto ao Programa de Iniciação Científica (PIBIC) da Universidade Federal da Bahia (UFBA).

A temática abordada envolve o debate da pratica pedagógica da Educação Física no contexto da educação do campo no nordeste brasileiro. Evidencia a importância dos estudos que possam caracterizar a realidade da Educação Física escolar em diferentes regiões do país visando à construção de proposições; bem como o enfrentamento e superação das problemáticas enfrentadas a partir no fazer pedagógico desta área do conhecimento.

O estudo foi realizado em áreas de reforma Agrária do MST na região do Recôncavo da Bahia. O objetivo geral da pesquisa foi analisar a realidade da prática pedagógica do jogo, enquanto conteúdo de ensino da Educação Física, na Escola do Assentamento Nova Panema. O problema de pesquisa que orientou o estudo foi sistematizado da seguinte forma: qual a realidade da prática pedagógica do conteúdo jogo na Escola do Assentamento Nova Panema, no período de 2009/2011?

Este trabalho apresenta inicialmente a análise da realidade da educação do campo e as particularidades do assentamento. Em seguida tratamos das considerações teóricas acerca da abordagem do conteúdo jogo. Finalmente, apresentamos os resultados do estudo a partir dos dados da realidade do trabalho escolar e abordagem do jogo na escola.

\section{Assentamento Nova Panema: análise da realidade da educação do campo brasileiro}

O atraso escolar no Brasil é evidente nos altos índices de reprovação e abandono, na desigualdade social, na baixa renda da população e na qualidade das escolas. Estas são apontadas como as principais causas do baixo desempenho dos estudantes brasileiros no Programa Internacional de Avaliação de Alunos (PISA), o qual tem como finalidade produzir indicadores sobre a efetividade dos sistemas educacionais e avalia o desempenho de alunos na faixa dos 15 anos, idade na qual se pressupõe o término da escolaridade básica obrigatória na maioria dos países. Em relação ao atual perfil da educação do campo esta realidade é ainda mais precária.

Conforme o estudo Panorama da Educação no Campo, elaborado pelo Instituto Nacional de Estudos e Pesquisas Educacionais Anísio Texeira/Ministério da Educação (INEP/MEC), em 2006, que utiliza dados da Pesquisa Nacional por Amostra de Domicílios (PNAD-2004), evidenciava que, no Brasil, menos de um quinto de sua população (17\%) vive no campo, o que equivale a 30,8 milhões de pessoas.

A escolaridade média dessa população, de 15 anos ou mais que vive na zona rural, corresponde apenas metade da estimada para a população urbana. Isto é, a escolaridade média dessa população era de 4,0 anos na faixa etária de 15 anos de idade ou mais, contra 7,3 anos da população da cidade. Ainda, temos o índice de 29,8\% de adultos analfabetos no campo, frente aos $8,7 \%$ na cidade. 
Ainda, conforme dos dados do INEP/MEC, entre os anos de 2003 e 2012, foram fechadas 29.459 escolas do campo no Brasil ${ }^{3}$. Esse processo desencadeou a campanha nacional "Fechar Escola é Crime", realizada pelo MST em conjunto com outros movimentos sociais do campo.

Este dado soma-se a realidade apresentada pelos índices do Censo Escolar de 2011, onde o Brasil apresenta 76,2 mil escolas rurais. Dentre essa totalidade, 42 mil são multisseriadas, quase $15 \%$ ainda não possuem energia elétrica, $89 \%$ não têm biblioteca e $81 \%$ não contam com laboratório de informática. Ainda, o levantamento do Fundo das Nações Unidas para a Infância (Unicef), feito com base na PNAD de 2009, mostrou que $2,5 \%$ das crianças e adolescentes que vivem no campo, entre a idade de 7 e 14 anos, estavam fora da escola.

Este contraditório, que tem a sua expressão na luta social do campo, através dos movimentos sociais populares do campo ${ }^{4}$, apresenta também seus distintos projetos societários em confronto no campo brasileiro. Considerando que os projetos societários, os modelos de desenvolvimento do campo e da agricultura estão interligados, podemos distinguir o campo do agronegócio e o campo da agricultura camponesa (MOLINA e JESUS, 2004).

O primeiro, historicamente hegemônico no país, aponta para a defesa da propriedade privada dos meios de produção, a não socialização dos bens produzidos coletivamente, o não planejamento da produção, e a despreocupação total em relação à destruição do meio ambiente.

O projeto vinculado ao campo da agricultura camponesa, defendido pela classe trabalhadora/campesina, almeja a socialização dos meios de produção, a distribuição igualitária dos bens produzidos coletivamente, a produção com base em um planejamento que vise atender às necessidades e demandas sociais. Ainda, busca recuperar a interação homem/natureza, também a partir da preservação do meio ambiente enquanto base de manutenção da vida humana, tal como na produção agrícola de base agroecológica.

Esta proposição para o desenvolvimento do campo brasileiro, esta diretamente vinculada às particularidades do projeto educacional do MST numa perspectiva omnilateral. A educação, que cumpre um papel estratégico para este MSP do C, é entendida enquanto um dos processos de formação da pessoa humana, que está sempre ligada com um determinado projeto político e com uma concepção de mundo. É compreendida como uma das dimensões da formação, tanto no sentido amplo da formação humana, como no sentido mais restrito de formação de quadros para a organização e para o conjunto das lutas dos trabalhadores (MST, 1996).

Neste sentido, ao reivindicar a sua própria pedagogia, o MST destaca que esta se caracteriza pelo modo através do qual o Movimento vem historicamente formando o

3 Ver impactos do fechamento das escolas do campo em MARIANO \& SAPELLI, 2014.

4 A terminologia 'Movimentos Sociais Populares do Campo (MSP do C) tem sido utilizada por estes movimentos sociais campesinos como o Movimento dos Trabalhadores Rurais Sem Terra (MST), Movimentos dos Atingidos por Barragens (MAB), Movimento dos Pequenos Agricultores (MPA), entre outros, inclusive para apresentar o recorte de classe existente em seus projetos político-sociais (ITERRA, 2004). 
sujeito social de nome Sem Terra, e educando as pessoas que fazem parte dele, no dia a dia de sua organização. Segundo o MST, o princípio educativo principal desta pedagogia é o próprio Movimento, onde o olhar para este processo pedagógico ajuda a compreender e fazer avançar as experiências de educação e de escola vinculadas ao MST.

Esta compreensão ampla de educação, apresentada pelo MST, pode ficar mais evidente e compreensível na seguinte afirmação: "O MST descobriu que os acampamentos e os assentamentos são uma Escola. A participação nas mobilizações e nas lutas educa o Sem Terra. Educação que é aprofundada pela reflexão sobre a vida, a prática" (MST, 2000, p. 05).

A educação para o Movimento, neste sentido, não se limita apenas às "paredes" da instituição escolar. Ao contrário, a educação é percebida como um processo constante que se dá de forma dinâmica na relação das pessoas com a realidade inserida, onde se entende a que a escola é mais do que escola na pedagogia do MST.

A educação não é tratada de maneira isolada de toda uma prática de militância pela transformação social, como se evidencia nos princípios apontados pela Pedagogia do Movimento. Conforme o MST, a educação é uma particularidade de um projeto mais amplo, pois

Com o MST, temos uma mística. Cultivamos símbolos. Temos um jeito de viver e um jeito de falar: ocupamos palavras. Temos um grande objetivo que é a Reforma Agrária. Objetivo este que só se realiza plenamente com o alvorecer de uma sociedade nova. Na caminhada para concretizar este objetivo descobrimos que a vivência dos NOSSOS VALORES ajuda a construir o caminho. Ajuda a resistir contra anti-valores semeados pela sociedade atual. Mais, os valores é que dão o tempero de nossa ação. Na vivência dos valores nos tornamos mais humanos e mais lutadores e lutadoras (MST, 2000, p. 05).

A proposta pedagógica do MST encontra-se no interior de uma luta ampla pela educação do campo, a qual deve ser de gratuita, de qualidade, e mantida pelo Estado. Para os MSP do C, “(...) A educação do campo precisa ser uma educação específica e diferenciada, isto é, alternativa. Mas, sobretudo, deve ser educação, no sentido amplo de processo de formação humana, que constrói referências culturais e políticas para a intervenção das pessoas e dos sujeitos sociais na realidade, visando a uma humanidade mais plena e feliz" (KOLLING, 1999, p. 23).

O MST foi fundado oficialmente em 1984 com a fusão das manifestações sociais localizadas. Ao questionar a concentração de terras, o MST apresenta a reforma agrária como pauta de luta dos movimentos do campo e incorpora as ocupações das propriedades fundiárias como um instrumento de luta.

Dessa forma “(...) o MST começou a se organizar na Bahia entre 1985-1986, e em 07 de setembro de 1987 aconteceu a sua primeira intervenção, 700 famílias ocuparam a gleba 40-45 de uma empresa da cidade de Itamaraju, no extremo sul, ficando marcado, assim, o principio da sua trajetória no Estado" (MST, 2007 apud TEIXEIRA, 2009, p. 127).

Através das ocupações realizadas em diversas áreas do Recôncavo Baiano foram criados três assentamentos no município de Santo Amaro, e quatro assentamentos na 
região de São Sebastião do Passé. Dentre estes, neste último município, encontra-se o Assentamento Nova Panema, local onde foi desenvolvida a pesquisa.

Este assentamento foi criado em 26 de outubro de 1999, e teve sua emissão de posse em janeiro do ano de 2000. A fase de acampamento, anterior a essa data, durou dois anos e enfrentou três ações de reintegração de posse.

Atualmente possui sua estrutura constituída por 58 casas que formam a agrovila, sendo que algumas famílias não moram continuamente no assentamento, visto que, para terem acesso às condições básicas de sobrevivência, se deslocam para trabalhar em empregos temporários nas fazendas da região ou nas cidades. Este fato decorre da histórica falta de condições efetivas para o desenvolvimento da reforma agrária, após o assentamento das famílias nas áreas de reforma agrária.

Este processo soma-se ao do fato de que o assentamento é estabelecido em uma área que foi dedicada durante trinta e cinco anos à plantação e extração de eucalipto. As conseqüências da exploração da monocultura de eucalipto são confirmadas pelo empobrecimento do solo da região, fator que gera, por exemplo, a baixa produtividade agrícola, que se encontra baseada principalmente na cultura da mandioca.

A educação escolar no assentamento também enfrenta diversas dificuldades que vão desde a limitação dos materiais pedagógicos à falta de um espaço escolar adequado para a realização das atividades. Durante os primeiros onze anos que se encontrou estabelecido o assentamento, a educação tem sido garantida pela iniciativa da comunidade. Inicialmente a escola funcionou a partir da construção do prédio escolar de 'taipa', que desabou no ano de 2005. Posteriormente, as atividades escolares passaram ao espaço físico da garagem da Associação de Produtores Rurais Nova Panema.

No ano de 2008, durante o segundo semestre letivo, ao iniciarmos atividades de ensino, pesquisa e extensão nesta área, a escola continuava em funcionamento nesta garagem da Associação, a qual se encontrava numa condição bastante precarizada. A Escola do Assentamento Nova Panema atendia aos estudantes da própria comunidade e dos assentamentos e acampamentos vizinhos.

No decorrer dos trabalhos realizados através da universidade, podemos acompanhar mutirões que foram sendo organizados junto à comunidade para recuperar o espaço da escola. As atividades desenvolvidas promoveram diversas oficinas pedagógicas de capacitação e formação política que também contribuíram para a auto-organização da comunidade local.

Concomitantemente, foram realizadas ações pelo conjunto do MST e da comunidade tais como ocupações, marcha dos Sem Terrinha, reuniões na prefeitura, encaminhamento de documentos, dentre outras. Estas ações reivindicavam questões básicas como a regularidade no fornecimento da merenda escolar, o fornecimento de material didático, a contratação da professora e inclusive a construção do prédio escolar.

Após muitas negativas quanto à demanda do prédio escolar, em agosto de 2011, uma das oficinas pedagógicas realizadas na comunidade culminou com a decisão de 
encaminhar uma petição no ministério público denunciando as condições existentes e colocando as reivindicações da comunidade. No mês seguinte, início de setembro, a prefeitura deu início à construção do prédio escolar, o qual foi inaugurado em maio de 2012.

O novo prédio foi construído com uma sala de aula, dois banheiros, uma cozinha e uma pequeníssima sala que seria para computadores a qual, diante do reduzido tamanho, teve seu uso inviabilizado para tal função. A escola vinha, sistematicamente, sendo organizada com uma turma multisseriada de $1^{\mathrm{a}}$ a $5^{\mathrm{a}}$ série do Ensino Fundamental, com cerca de vinte e cinco estudantes na faixa etária de cinco a quatorze anos.

Em 2012 teve início uma turma de educação infantil. Porém, a mesma foi encerrada poucos meses depois frente à justificativa de que a prefeitura não poderia manter uma turma com um número pequeno de educandos. Ainda a professora não seria remunerada para trabalhar em dois turnos. Da mesma forma, a cada ano que se iniciava, dava-se início a uma turma de Educação de Jovens e Adultos (EJA), com uma média de dez estudantes matriculados. Contudo, ao longo do ano, estas turmas de EJA, eram fechadas devido à evasão e/ou motivos distintos.

Novamente, em 2014, definitivamente, todas as atividades da escola foram suspensas pela Secretaria Municipal de Educação, do Município de São Sebastião do Passe, a qual alegou que o número total de alunos naquele ano era insuficiente para a manutenção de uma turma de séries iniciais naquela região. Podemos observar neste fato a política geral de fechamento das escolas do campo impactando diretamente no local.

A escola foi fechada e as crianças passaram a se deslocar com ônibus escolares para escolas urbanas da região, dispensando aproximadamente duas horas diárias em deslocamentos. Além disso, em épocas de chuvas intensas, as crianças não podiam ir à escola devido à falta do transporte ocorrido pelas precárias condições das estradas locais, que não possuem asfaltamento.

Diante desse contexto da realidade da educação do campo, podemos levantar algumas questões reflexivas: como esta a realidade da Educação Física Escolar nas escolas do campo? Os conteúdos desta área do conhecimento estão sendo acessados por nossas crianças e jovens que vivem no campo brasileiro?

A partir destas reflexões, delimitamos para análise a realidade da Educação Física na escola a partir da especificidade de um dos conteúdos da cultura corporal, o conteúdo jogo. Para tanto, abordaremos a seguir os elementos teóricos que fundamentam o debate deste conhecimento a partir de diferentes referenciais.

\section{As Teorias Pedagógicas para a Abordagem do Conteúdo Jogo: considerações teóricas}

Ao iniciarmos uma investigação sobre o jogo, podemos observar a diversidade de autores que realizaram estudos sobre o tema, expressando diferentes pontos de vista. Conforme Brunhs (1999), este fato pode traduzir uma considerável dificuldade em defini-lo. E esses diferentes pontos de vista aparecem expressos nas teorias elaboradas por diversos 
autores, tais como Huizinga, Piaget, Chateau, Winnicott e Vigotsky, que destacaram os aspectos mais significativos do jogo de acordo com o seu campo de estudo.

Algumas teorias sobre o lúdico foram amplamente desenvolvidas nos espaços de discussão do assunto, e especialmente, apresentam-se refletidas na abordagem do jogo no espaço escolar. Dentre as teorias apresentadas por Brunhs na obra 'O Corpo Parceiro e o Corpo Adversário' (1999), destacam-se a teoria da 'energia excedente', a 'teoria da recreação' e a teoria do 'pré-exercício'.

Conforme a autora, a "teoria da energia excedente" explica que as crianças e os animais, quando pequenos, são inteiramente dependentes e protegidos pelos país possuindo, portanto, energia excedente. A crítica feita em relação a essa teoria explica que as atividades dos animais apresentam objetivos claros e definidos. Quanto às crianças, dificilmente a energia que possuem pode ser considerada de "excedente", uma vez que jogam pelo interesse demonstrado.

Já a "teoria da recreação" tem um caráter funcionalista no sentido de colocar o homem à mercê do sistema social ao qual este pertence, colaborando sempre para a manutenção do status quo. O jogo é compreendido como uma representação orgânica das forças despendidas, podendo cumprir um papel necessário para que os sujeitos se reanimem após o trabalho.

Ainda, segundo Brunhs (1999), a "teoria do pré-exercício", compreende que o jogo seria a finalidade da infância, bem como uma espécie de treino para o desenvolvimento da inteligência. Dentro dessa teoria, o jogo é analisado como preparação para o trabalho ou para a vida adulta.

A crítica dirigida pela autora expressa que,

De maneira geral, essas teorias oferecem visões parciais do fenômeno, colocando
basicamente a importância na hereditariedade, em aspectos biológicos e fisiológi-
cos. Partem dos indivíduos numa situação evolutiva, não considerando a vida do
homem em sociedade, e sua cultura influenciando-o nas suas ações. Para melhor
compreensão e uma crítica mais apurada, deveria ser considerado o momento his-
tórico no qual foram elaborados, pois dessa forma seria percebida a intenção sus-
tentada pelos valores dominantes na época do surgimento (BRUNHS, 1999, p. 26).

Ampliando a crítica sobre essas teorias do jogo, Johan Huizinga (1993) acrescenta que “(...) todas elas partem do pressuposto de que o jogo se acha ligado a alguma coisa que não seja o próprio jogo, que nele deve haver alguma espécie de finalidade biológica. Todas elas se interrogam sobre o porquê e os objetivos do jogo...", ou seja, "(...) preocupa-se apenas superficialmente em saber o que o jogo é em si mesmo e o que ele significa para os jogadores" (HUIZINGA, 1993, p. 4-5).

Nesse sentido, o autor compreende que o jogo apresenta características que o definem enquanto um fenômeno cultural, ou seja, “(...) o jogo como forma específica de atividade, como 'forma significante', como função social" (ibidem, p. 06). Segundo Huizinga, isto não significa analisar propriamente os impulsos e hábitos naturais que 
condicionam o jogo em geral, mas analisar os significados que os jogos apresentam durante o desenvolvimento da sociedade humana ao longo da história.

Essas teorias destacam-se entre aquelas que mais influenciaram a elaboração de propostas pedagógicas que subsidiaram a abordagem do jogo na instituição escolar, principalmente no Brasil.

A partir do século XIX com a criação dos jardins-de-infância no Brasil, os jogos passaram a ser introduzidos no contexto escolar, sendo ora compreendidos "como ação livre da criança, ora como atividade orientada pelo professor na busca de conteúdos escolares". (KISHIMOTO, 2009, p. 99). Segundo a autora, essas instituições escolares foram fortemente influenciadas pelos estudos de Froebel e, posteriormente, pelos princípios educacionais do movimento denominado Escola Nova representado por Claparède, Dewey, Decroly e Montessori.

Conforme Kishimoto (2009, p. 103), os “(...) jardins-de-infância froebelianos incluem jogos nos quais se permite às crianças uma livre exploração, oferecendo apenas o suporte material e jogos orientados nos quais há uma clara cobrança de conteúdos a adquirir". A prática pedagógica desses jogos era desenvolvida a partir de brincadeiras de roda que tratavam de temáticas variadas (tais como, estações do ano, flores etc.), sendo acompanhadas pela movimentação das crianças conforme a música.

Nesse sentido, o papel educativo dos jogos constitui uma possibilidade de facilitar o conhecimento espontâneo das crianças sobre os elementos do ambiente que a cercam, bem como apresentar "efeitos positivos na esfera cognitiva, social e moral" (KISHIMOTO, 2009, p. 102).

A partir da década de 1920 com a expansão do movimento Escola Nova, os jogos educativos passam a ser incorporados na escola em detrimento dos jogos livres desenvolvidos pelas crianças. A psicologia funcionalista de John Dewey, principal autor desse movimento, divulgada no Brasil especialmente por Claparède, compreende o jogo como manifestação de interesses e necessidades da criança.

Neste sentido, a criança procura o jogo como uma necessidade e não como distração, sendo que a criança se revela através do jogo. As suas inclinações, a sua vocação, tanto quanto suas habilidades e seu caráter, latentes no seu eu em formação, tornam-se visíveis pelo jogo e pelos brinquedos que ela executa (KISHIMOTO, 2009).

Nessa época histórica destaca-se uma ênfase da utilização dos jogos de uma forma diretiva para o ensino de conteúdos escolares, principalmente em escolas da rede pública de ensino. Essa orientação do movimento escolanovista será incorporada a prática pedagógica da Educação Física escolar, sendo "estimulada à perspectiva do jogo enquanto recreação, uma atividade orientada que colabora com o desenvolvimento físico e higiênico da criança" (KISHIMOTO, 2009, p.109).

Segundo Tavares e Souza Júnior (2007), o jogo ao ser incorporado como atividade no interior das aulas de Educação Física apresenta significados distintos relacionados aos objetivos pretendidos com a sua prática e a metodologia utilizada para a sua abordagem. Dessa forma, 
O jogo aparece como momento de descontração de aulas altamente disciplinadas; o jogo aparece como instituição esportiva, sendo exigido o rendimento técnico; o jogo aparece enquanto momento de lazer, de brincadeira caracterizando como catarse de um ensino autoritário; o lazer aparece enquanto premiação após a realização de sessões de aulas com alto índice de desgaste físico; o jogo aparece enquanto conteúdo mais adequado a ser trabalhado com os alunos: queimado para as meninas e futebol para os meninos (TAVARES; SOUZA JÚNIOR, 2007).

A partir das análises dos distintos autores, sublinhamos a abordagem do jogo na especificidade da Educação Física escolar. As discussões estabelecidas, em meados da década de 1980, problematizaram amplamente o conceito e o objeto de estudo desta área do conhecimento, resultando numa ampla sistematização de diferentes abordagens e proposições para o ensino.

Nessas abordagens são apresentadas algumas considerações sobre o entendimento do jogo e o seu papel pedagógico na escola. Dentre outras destacamos a abordagem construtivista-interacionista, proposta por João Batista Freire (1989); a proposta dos jogos cooperativos proposta por Fábio Otuzi Brotto $(1997,1999,2001)$ e a crítico-superadora divulgada na obra do Coletivo de Autores (1992).

A abordagem construtivista-interacionista, que tem como principal elaborador o professor João Batista Freire, está sistematizada na obra "Educação de Corpo Inteiro", publicado em 1989.

Segundo Darido (2003, p. 07), o autor dessa obra vem “(...) resgatar a cultura dos jogos e brincadeiras dos alunos envolvidos no processo ensino-aprendizagem, aqui incluídas as brincadeiras de rua, os jogos de regras, as rodas cantadas e outras atividades que compõem o universo cultural dos alunos". Na análise da autora, nessa proposta, o jogo enquanto conteúdo/estratégia de ensino é considerado “(...) o principal modo de ensinar, é um instrumento pedagógico, um meio de ensino, pois enquanto joga ou brinca a criança aprende" (ibidem, p.08).

Ainda assim, segundo Darido (2003), o que não fica esclarecido nessa discussão é qual o conhecimento que se deseja construir através da prática da Educação Física, uma vez que a abordagem construtivista-interacionista defende “(...) que o movimento poderia ser um instrumento para facilitar a aprendizagem de conteúdos diretamente ligados ao aspecto cognitivo, como a aprendizagem de leitura, da escrita e da matemática, etc." (ibidem, p. 06).

A proposta dos jogos cooperativos tem sido divulgada no Brasil por Fábio Otuzi Brotto, principalmente a partir de seus trabalhos "Jogos Cooperativos: se o importante é competir o fundamental é cooperar!" de 1997 e "Jogos Cooperativos: o jogo e o esporte como um exercício de convivência", publicada em 2001.

Segundo Darido (2003), essa proposta de abordagem sugere que os jogos cooperativos possuem uma força transformadora, criando valores de cooperação em contraposição ao grau de competitividade presente nos jogos que apresenta o divertimento a partir da derrota de um dos jogadores.

Finalmente, a perspectiva crítico-superadora defende que os conhecimentos da expressão corporal sejam tematizados na escola como cultura corporal, isto é, os conhecimentos devem ser abordados considerando a sua gênese e desenvolvimento histórico. 
Dessa forma, no livro "Metodologia do Ensino da Educação Física", de 1992, são apresentados os conteúdos de ensino da Educação Física sistematizados e organizados através de temas, dentre os quais, apresenta-se uma proposta para a abordagem pedagógica dos jogos.

Essa proposta considera que a ação pedagógica deve ser estruturada de forma que o jogo possa ser entendido, aprendido, refletido e reconstruído enquanto conhecimento da humanidade, possibilitando a sua constatação, sistematização, ampliação e aprofundamento do mesmo (COLETIVO DE AUTORES, 1992).

Tendo como base a perspectiva crítico-superadora da Educação Física, Tavares e Souza Júnior (2010) apresentam uma sistematização mais específica sobre o jogo enquanto conhecimento. Nessa proposta os jogos são classificados nos seguintes grupos: jogos de salão, jogos populares e jogos esportivos. A presente classificação dos jogos proposta por Tavares e Souza Júnior (2010), possibilita a abordagem dos jogos na escola a partir dos elementos que retratam fundamentalmente os seguintes aspectos: a origem dos jogos, o local de realização das atividades, as regras que orientam a realização dos jogos, etc.

Essa proposta de abordagem do jogo se configura a partir do entendimento de que o jogo, enquanto um conhecimento produzido historicamente pela humanidade deve ser abordado na escola a partir do resgate histórico de sua origem e desenvolvimento, das características que o fundamentam e do seu papel na cultura popular de determinada região.

Considerando esses elementos será a seguir analisada a realidade da escola do Assentamento Nova Panema, destacando-se como o conteúdo jogo vinha sendo abordado com os estudantes da turma multisseriada da escola, no respectivo período delimitado no estudo.

\section{Os dados da realidade do Trabalho Escolar e da Abordagem do Conteúdo Jogo na Escola}

A partir da sistematização dos dados da realidade da educação escolar no assentamento em questão, oriunda desde o desenvolvimento das ações permanentes na referida área, a partir de 2008 através da UFBA, delimitamos o recorte da pesquisa para analisar a prática pedagógica da Educação Física na escola.

Dentre os conhecimentos que constituem a cultura corporal, delimitamos o conteúdo jogo como objeto de análise e sistematização das experiências pedagógicas com a turma multisseriada, das séries iniciais do Ensino Fundamental.

O objetivo geral do estudo foi analisar a realidade da prática pedagógica do jogo, enquanto conteúdo de ensino da Educação Física, na Escola do Assentamento Nova Panema, no período de 2009/2011. E buscamos responder a pergunta "qual a realidade da prática pedagógica do conteúdo jogo na Escola do Assentamento Nova Panema", no período delimitado.

A metodologia da pesquisa desenvolvida utilizou como instrumentos de coleta de dados a observação participante, registros fotográficos e de campo, análise de documentos e entrevista semi-estruturada. Ainda, envolveu como aporte teórico as categorias de análise do materialismo histórico dialético. 
Dessa forma, alguns elementos importantes para a compreensão da realidade escolar no assentamento, e especificamente da turma multisseriada do Ensino Fundamental, são apresentados pelas próprias professoras nas duas entrevistas. A professora que atuou na escola no decorrer do ano de 2009 será identificada como professora Maria. Já a professora que atuou durante o ano de 2010 será identificada como professora Suzana5.

Nas análises dessas entrevistas, destacamos as seguintes categorias: a) formação do professor; b) planejamento; c) conteúdos escolares; d) avaliação; e) gestão escolar e f) a Educação Física na escola. Cada um desses elementos será discutido de forma detalhada a seguir.

Inicialmente, um dos principais fatores que dificultam e impactam o trabalho pedagógico na escola do assentamento é a mudança contínua dos professores, o que acarretou na descontinuidade dos trabalhos com os educandos, bem como a formação profissional de acordo com a proposta de educação do Movimento.

Essa afirmação é confirmada ao analisarmos que durante os primeiros três anos de atividades do projeto de extensão na comunidade, a cada ano ocorria uma mudança de professores, sendo que no último período de 2011, não conseguimos realizar aproximações permanentes com a professora da escola.

A escola contava com um corpo de trabalhadoras constituído pela professora, que era contratada apenas durante e a cada novo período letivo; e uma merendeira que, em 2010, realizava trabalhos voluntários iniciados há cerca de cinco anos. Ambas residiam na própria comunidade e contribuíam com a organização das atividades escolares. Com a denúncia do ministério público, a merendeira teve finalmente a assinatura de um contrato temporário, a partir de outubro de 2011, com duração apenas para cada período letivo.

A seguir, passaremos a apresentar os resultados encontrados, a partir da delimitação e observação das categorias empíricas selecionadas.

\section{a) A Formação do professor(a)}

A Secretaria de Educação de São Sebastião do Passé estabelece como critério para contratação de professor a formação mínima em Magistério ou, então, a formação superior em Pedagogia.

A professora Maria, que atuava na escola do assentamento em 2009, possuía formação no Curso de Magistério e, nesse período tinha iniciado os estudos no curso de Pedagogia em uma universidade particular de Educação à Distância, no município de Mata de São João, Bahia. Apesar do incentivo da Secretaria de Educação visando que a professora buscasse formação na educação superior, a única contribuição dada pela Secretaria era a liberação da professora no período da sexta-feira à noite.

Neste turno ela deveria estar com a turma de EJA, mas então era liberada para ela poder se deslocar até o Município de Mata de São João, localizado a 10 quilômetros da área, local onde ocorria o curso em andamento.

5 Nomes fictícios para fins de identificação da presente pesquisa. 
No entanto, a professora Suzana, que a substituiu no ano posterior, em 2010, havia se formado no curso de Magistério no ano de 2000. Esta tinha experiência apenas com uma turma de $4^{\mathrm{a}}$ série do Ensino Fundamental, realizada durante o seu período de estágio no curso. A reduzida experiência com o ensino, segundo a própria professora, dificultava o desenvolvimento do trabalho na escola, principalmente se tratando de ensinar para uma turma multisseriada.

Conforme destaca a professora Suzana, torna-se necessária a realização de um curso de capacitação de professores para trabalhar com turmas multisseriadas da escola do campo. Mas o fato é que a Secretaria de Educação de São Sebastião do Passé à época, não desenvolvia esses cursos no município, ou pouco divulgava atividades de capacitação pedagógica.

Esse elemento é confirmado durante o ano de 2010 quando, segundo a professora, foi realizada uma oficina de capacitação de professores para trabalhar com as turmas de EJA, a qual ela recebeu informação apenas através de um colega de trabalho, no mesmo dia em que iria ocorrer o evento. Por outro lado, mais um exemplo citado foi o curso de informática o qual ela pôde participar devido à necessidade da Secretaria de Educação, que iria instalar computadores nas escolas. Para tanto requisitaria a capacitação das professoras para a utilização e manutenção desse instrumento.

\section{b) O Planejamento}

O planejamento das atividades escolares, até o final de 2012, quando finalizou a gestão da prefeitura municipal, vinha sendo orientado por uma coordenadora pedagógica da Secretaria de Educação de São Sebastião do Passé. Esse planejamento era realizado quinzenalmente, no qual a professora discute e apresenta o plano de trabalho que seria desenvolvido com a turma do Ensino Fundamental.

A professora Maria, que atuava na escola em 2009, considerava a realidade dos educandos como ponto de partida fundamental, para o planejamento das atividades, enquanto forma de aproximar os conteúdos de ensino da escola. Contudo, além das dificuldades do trabalho com uma turma multisseriada, a professora destacava que a utilização dos livros didáticos enviados pela Secretaria de Educação retrata a realidade do contexto urbano, não levando em consideração a realidade do campo.

A professora Suzana, atuante na escola em 2010, enfocava o planejamento das atividades apenas nos conteúdos que constavam no projeto da escola, portanto não levando em consideração a realidade dos educandos. Esse fato, segundo a professora, devia-se principalmente ao fato de residir no assentamento apenas nos dias de trabalho, e não ser uma moradora permanente no local. Tal fator, em sua análise, limitava o aprofundamento do contato com a realidade local e com a maioria das crianças que freqüentavam a escola.

Mas o fator em destaque, em ambas as entrevistas, foi à dificuldade de realizar um planejamento das atividades para a turma Multisseriada do Ensino Fundamental que contemplasse todas as séries e os diversos "níveis" de desenvolvimento dos estudantes. 
julho/2017

Apesar da orientação para o planejamento, recebida através da coordenadora pedagógica da Secretaria de Educação do município, as dificuldades para organizar o trabalho com essa turma, a partir das séries mais próximas, era algo permanente.

\section{c) Os Conteúdos Escolares}

Na análise do Projeto Político-Pedagógico (PPP) da Escola do Assentamento Nova Panema verificou-se que a organização curricular do primeiro ao quarto ano do Ensino Fundamental, visa ao cumprimento das orientações elaboradas pela Lei de Diretrizes e Bases da Educação Nacional (LDB). Nesse sentido, os conteúdos programáticos abordam as seguintes áreas do conhecimento: Língua Portuguesa, Matemática, História, Geografia, Ciências e Ensino Religioso/Filosofia.

Conforme podemos observar, a Educação Física não consta dentre os conteúdos obrigatórios, ou garantidos e orientados pela legislação brasileira para as séries iniciais do ensino fundamental. E, neste caso, como uma das importantes constatações, esta disciplina também não consta dentre os conhecimentos propostos pelo PPP da Escola Nova Panema, o qual segue as orientações da LDB.

Porém, aqui se evidencia uma importante contradição, considerando-se que a LDB, em seu artigo 26, destaca que "Os currículos da educação infantil, do ensino fundamental e do ensino médio devem ter base nacional comum, a ser complementada, em cada sistema de ensino e em cada estabelecimento escolar, por uma parte diversificada, exigida pelas características regionais e locais da sociedade, da cultura, da economia e dos educandos" ${ }^{\prime \prime}$. E complementa com o parágrafo terceiro deste artigo que "(...) A educação física, integrada à proposta pedagógica da escola, é componente curricular obrigatório da educação básica (...)" (MEC, 1996).

Conforme destacado anteriormente, a dificuldade para a abordagem desses conteúdos na escola do assentamento encontra-se no fato de que, a turma de séries iniciais do Ensino Fundamental organiza-se em uma turma mutisseriada.

Nesse sentido, os professores precisam ocorrer às diversas estratégias para garantir o ensino dos conteúdos nos diferentes níveis e seriações respectivas. Uma das estratégias utilizadas tratava-se de dividir a turma nas séries mais aproximadas e direcionar o conteúdo específico para cada grupo organizado.

\section{d) Avaliação}

Em relação à avaliação realizada pela professora da escola, a professora Maria, que atuou durante o ano de 2009, relatou que inicialmente utilizou a aplicação de provas bem como trabalhos em grupos. Já nas unidades posteriores, além de utilizar os instrumentos de

6 Redação dada pela Lei nº 12.796, de 2013. 
avaliação já citados, também foi desenvolvida a avaliação processual, na qual, a professora, observava o desenvolvimento dos estudantes durante as atividades escolares.

Durante o ano letivo de 2010, a avaliação do ensino realizada pela professora Suzana foi baseada na aplicação de provas, trabalhos individuais e em grupo. A docente destacou que sua avaliação tinha como base as provas escritas e que os elementos como participação e interesse são "obrigações" dos estudantes com a sua aprendizagem.

\section{e) Gestão escolar}

A partir dos documentos analisados, consta no quadro de funcionários da Escola do Assentamento Nova Panema, mantida pela Secretaria de Educação de São Sebastião do Passé, consta a existência de apenas dois funcionários: uma professora - a qual é contratada semestralmente para ministrar as aulas para uma turma multisseriada das primeiras séries do Ensino Fundamental e para uma turma de Educação de Jovens e Adultos (EJA); e um funcionário indicado pela Secretaria de Educação - a qual exercia as funções de coordenadora pedagógica e de diretora da escola.

Ainda, somente em 2011, com o ajuizamento da ação no ministério público, conforme historicizado anteriormente, a Secretaria de Educação contratou temporariamente a moradora da área. Esta já desenvolvia a função de merendeira na escola, de forma voluntária, há pelo menos cinco anos.

As condições de contratação, referentes a professoras e a merendeira, presentes diariamente na rotina da escola, evidenciavam a contratação precarizada, sem a garantia dos direitos trabalhistas, bem como falta de condições adequadas para o desenvolvimento do trabalho.

A professora Maria, contratada no ano de 2009, era residente da área. Porém mudou-se para a cidade após a finalização daquele ano letivo. Já a professora Suzana, que atuou na escola durante o ano de 2010, residiu em casa de parentes, semanalmente, durante o período em que ministrava as aulas. Aos finais de semana ela se deslocava para sua residência localizada no município próximo a 10 quilômetros da área.

Em relação à outra funcionária, esta residia no Município de São Sebastião do Passe e desempenhava o cargo de acompanhamento pedagógico das escolas do campo e de diretora, atendendo também esta função na referida escola do assentamento.

Quinzenalmente, essa funcionária, que está vinculada à coordenação da educação do campo da Secretaria Municipal de Educação, realizava visitas às escolas do campo, desenvolvendo o acompanhamento bem como o planejamento das atividades juntamente com o professor local. Já a coordenação geral da Educação do Campo no município realizava visitas a cada três meses.

A coordenação pedagógica realizava o acompanhamento das atividades desenvolvidas pelas professoras de diversas maneiras: a análise do plano de trabalho semanal; a aplicação de uma prova municipal para avaliar o desenvolvimento dos estudantes; e ainda implementação da Provinha Brasil (avaliação do ensino fundamental realizada pelo Governo Federal). 


\section{f) A Educação Física na Escola}

Na análise do projeto político-pedagógico da Escola do Assentamento Nova Panema verificamos que a Educação Física não constitui um componente curricular nas atividades escolares. Todavia, alguns conhecimentos da cultura corporal são citados neste documento como um meio para discutir os conteúdos relacionados às outras disciplinas curriculares, especificamente em Ciências, Língua Portuguesa e Geografia.

Na elaboração dos conteúdos programáticos para a disciplina Ciências, primeiro ano do ensino fundamental, consta a citação do esporte na abordagem da temática "Partes do Corpo Humano". No documento o esporte é compreendido como um instrumento para o desenvolvimento do corpo sadio, juntamente com a discussão sobre a alimentação e higiene.

Na disciplina Língua Portuguesa, elaborada para o segundo e terceiro ano, consta como tema a ser abordado o "recontar e reproduzir oralmente histórias, brincadeiras, jogos...". Esse elemento é enfatizado também pelo Caderno de Educação do MST intitulado "Como fazer a escola que queremos: o planejamento", enquanto conteúdo básico a ser trabalhado nas primeiras séries do Ensino Fundamental em uma escola de assentamento a partir do "(...) resgate de jogos e cantigas, bem como brincadeiras populares da região" (MST, 2002, p. 42).

Ainda, no que diz respeito ao conteúdo da disciplina Geografia, para o terceiro ano do Ensino Fundamental, constava como a discussão sobre as "diferenças existentes entre o espaço urbano e o rural em relação à moradia, hábitos cotidianos, lazer e meios de transportes".

Considerando que a Educação Física não era um componente curricular na Escola do Assentamento Nova Panema, alguns dos seus conhecimentos, especificamente os jogos e as mímicas, eram abordados por iniciativa de ambas as professoras que lecionaram na escola em 2009 e 2010.

Em relação à abordagem do jogo na escola desenvolvida pela professora Maria durante o ano de 2009, conforme a entrevista realizada, a sua utilização estava relacionada aos seguintes objetivos: a) como recreação nos períodos de intervalo entre as aulas; b) como uma forma de "extravasar a energia excedente"; c) e, principalmente, como um instrumento para o ensino dos conteúdos escolares, como por exemplo, a partir do desenvolvimento do jogo 'Amarelinha' um dos estudantes aprenderem a escrita dos números.

A utilização do jogo enquanto um instrumento pedagógico, para o desenvolvimento dos conteúdos escolares de outras disciplinas, foi também reforçada através do trabalho pedagógico pela professora Suzana, que atuou na escola em 2010. Esta destacou que a abordagem dos jogos, durante as aulas, é desenvolvida a partir dos materiais pedagógicos enviados pela Secretaria de Educação de São Sebastião do Passé, dentre os quais se encontra "caça-palavras, essas letrinhas para formar sílabas, o ábaco".

Conforme podemos observar, a realidade evidencia local da educação do campo evidencia os limites na perspectiva da formação humana dos sujeitos e dos povos do campo, considerando os impactos da negação das condições básicas para o acesso a educação, e diversos importantes conteúdos, como arte, música, educação física, filosofia, etc. 


\section{CONSIDERAÇÕES FINAIS}

O estudo nos demonstrou as grandes dificuldades enfrentadas na particularidade da educação do campo no Brasil e a continuidade da negação do acesso aos bens básicos para a formação omnilateral dos seres humanos.

Na especificidade do presente trabalho, os dados da realidade evidenciam a negação e precarização das condições de oferecimento da educação, bem como dos conteúdos da Educação Física as crianças e jovens que residem em áreas do campo nos país.

Ao retomarmos a questão que orientou a pesquisa, acerca de qual a realidade da pratica pedagógica do conteúdo jogo na Escola do Assentamento Nova Panema, no período de 2009/2011, os resultados apontaram que a Educação Física não consta como componente curricular no projeto político-pedagógico da escola. O conteúdo jogo estava presente na prática pedagógica da professora da turma multisseriada, das séries iniciais do ensino fundamental.

Entretanto, a realidade da prática pedagógica do jogo na Escola do Assentamento Nova Panema, encontra-se vinculada a utilização do jogo enquanto: a) um instrumento pedagógico para o trato com o conhecimento de outros componentes curriculares; b) como uma atividade recreativa desenvolvida no período de intervalo entre as aulas; e c) como um momento de "extravasar a energia" preparando para as atividades que exigem maior concentração do estudante.

Esses dados nos indicam uma possível aproximação e permanência, de uma pedagogia escola novista e, portanto, funcionalista, na qual o uso de jogos educativos foi incorporado na escola, muitas vezes de forma diretiva para o ensino dos conteúdos escolares. Esse movimento teve ênfase na escola pública, e o uso do jogo nesta perspectiva deu-se em detrimento dos jogos livres desenvolvidos pelas crianças. E, ao ser incorporada na prática pedagógica da Educação Física estimulou o jogo como recreação, de forma orientada, visando o desenvolvimento físico e higiênico das crianças.

Não queremos dizer que o jogo não possa ser utilizado em outros componentes curriculares. Ao contrário, também devem ser estimulados e utilizados, porém de forma crítica e transformadora, somando-se a sua abordagem e garantia de acesso enquanto conteúdo específico da Educação Física escolar.

No campo específico da Educação Física, a pesquisa demonstra a necessidade de experimentações e sistematizações de propostas de ensino da Educação Física nas escolas do campo, e especialmente acerca da abordagem do jogo como conteúdo de ensino dessa área do conhecimento, visando superar a redução da sua utilização na escola apenas como um instrumento de ensino ou como atividade recreativa.

Por outro lado, no que diz respeito às políticas mais gerais para a educação nos país, o estudo evidencia a contradição e a necessidade da garantia de fato, e real, dos pressupostos constituintes da legislação do país, através dos governos municipais, estaduais ou federal. Isto é, dos direitos básicos de acesso à educação de qualidade, bem como o acesso aos conhecimentos das diferentes áreas do conhecimento, que devem ser garantidas na instituição escolar. 
julho/2017

\section{REFERÊNCIAS}

BRUHNS, H. T. O corpo parceiro e o corpo adversário. 2. ed. Campinas: Papirus, 1999.

BROTTO, F. O. Jogos cooperativos: o jogo e o esporte como um exercício de convivência, 1999. 209 f. Dissertação (mestrado) - Faculdade de Educação Física, Universidade Estadual de Campinas, Campinas, SP, 1999.

BROTTO, F. O. Jogos cooperativos: se o importante é competir, o fundamental é cooperar. Santos, SP: Projeto Cooperação, 1997.

BROTTO, F. O. Jogos Cooperativos: o jogo e o esporte como um exercício de convivência. Santos, SP: Projeto Cooperação, 2001.

COLETIVO DE AUTORES. Metodologia do Ensino da Educação Física. São Paulo: Cortez, 1992.

DARIDO, S. C. Educação Física na Escola: questões e reflexões. Rio de Janeiro: Guanabara Koogan, 2003.

FERNANDES, B. M. Brasil: $\mathbf{5 0 0}$ anos de luta pela terra. Disponível em: < http://gipaf. cnptia.embrapa.br/publicacoes/artigos-e-trabalhos/fernandes99.zip/view $>$. Acesso em: 21 dez. 2009.

FREIRE, J. B. Educação de Corpo Inteiro - teoria e prática da Educação Física. São Paulo, Scipione, 1989.

GADOTTI, M. Concepção dialética da educação: um estudo introdutório. 11. ed. São Paulo: Cortez, 2000.

HUIZINGA, J. Homo Ludens: o jogo como elemento da cultura. São Paulo: Perspectiva, 1990.

ITERRA. Instituto de Educação Josué de Castro - Método Pedagógico. Cadernos do Iterra. Ano IV, No. 9, Veranópolis, Iterra, Dez. 2004.

KISHIMOTO, T. M. Jogos infantis: o jogo, a criança e a educação. Rio de Janeiro: Vozes, 2003.

KOLLING, E. J. et al. (Org.). Por uma educação básica do campo. Brasília, DF: UnB, 1999.

MARIANO, A. S. \& SAPELLI, M. L. S. Fechar Escola é Crime Social: causas, impacto e esforços coletivos contra o fechamento de escolas no campo. 6o. Anais do Seminário Nacional Estado e Políticas Sociais. 15 a 18 de Setembro de 2014. Unioeste, Campus de Toledo, Paraná. 16 pgs.

MEC. Lei de Diretrizes e Bases da Educação Nacional. Brasília: 1996. Disponível em http://www.planalto.gov.br/ccivil 03/Leis/L9394.htm. Acesso em 28 de maio de 2016. MOVIMENTO DOS TRABALHADORES RURAIS SEM TERRA. Princípios da Educação no MST - Cadernos de Educação no. 08. ANCA, São Paulo, 1996.

MOVIMENTO DOS TRABALHADORES RURAIS SEM TERRA. Nossos Valores - Pra Soletrar a Liberdade no. 01. ANCA, São Paulo, 2000.

MOVIMENTO DOS TRABALHADORES RURAIS SEM TERRA. Como fazemos a escola de educação fundamental. Caderno de Educação no. 09. $2^{\mathrm{a}}$ ed, ITERRA, Veranópolis, 2001. MOLINA, M. e JESUS, S. M. S. A de (Orgs.) Por uma educação do campo. Contribuições para a construção de um projeto de educação do campo. n. 5., Brasília-DF: Articulação nacional "Por uma educação do campo", 2004, p.85. 
TAVARES, M.; SOUZA JÚNIOR, M. O jogo como conteúdo de ensino para a prática pedagógica da Educação Física na escola. Disponível em: < http://educacaofisica.org/ joomla/index.php? Itemid $=2 \&$ id $=150 \&$ option $=$ com_content $\&$ task $=$ view $>$. Acesso em: 06 de setembro de 2010.

TEIXEIRA, D. R. A necessidade histórica da cultura corporal: possibilidades emancipatórias em áreas de reforma agrária - MST/Bahia. Florianópolis: UFSC, 2009, 245 f. Dissertação de Mestrado, Programa de Pós-graduação em Educação, Centro de Ciências da Educação da Universidade Federal de Santa Catarina, Florianópolis, 2009.

TRIVIÑOS, A. N. S. Introdução à pesquisa em Ciências Sociais: a pesquisa qualitativa em educação: o positivismo, a fenomenologia, o marxismo. São Paulo, SP: Atlas, 1987.

Recebido em: junho/2016 Aprovado em: novembro/2016 